\title{
Abstracts Accepted for Publication
}

\section{Patient information and education}

\section{AB1250-PARE LOVE YOUR HEART - AN INTERACTIVE ON-LINE EDUCATION PROGRAMME TO ENABLE PEOPLE WITH RHEUMATOID ARTHRITIS TO ASSESS THEIR CARDIOVASCULAR RISK AND SET PERSONAL GOALS TO IMPROVE THEIR CARDIOVASCULAR HEALTH}

H. John ${ }^{1}$, A. Bosworth ${ }^{2} .{ }^{1}$ Rheumatology, The Dudley Group NHS Foundation Trust, Dudley; ${ }^{2}$ CEO, National Rheumatoid Arthritis Society, Maidenhead, United Kingdom

Background: Rheumatoid arthritis (RA) is associated with an increased risk of cardiovascular disease, akin to type 2 diabetes. However, screening for, management of, and education about co-morbidities is not always adequate and as a result, the co-morbid risks may be overlooked by the general public, some health professionals and policymakers alike. Dr. John originally developed and piloted a programme in group format in Dudley to educate RA patients about their cardiovascular risk and help them change their lifestyle to improve their health; it achieved promising results. The format however limited the number of people who could access it and NRAS wanted to make it as widely available as possible. The sad reality is that it is not unusual to meet someone with RA who does not realise that they are at an increased risk of heart disease, so they are far less likely to address factors such as smoking, weight and diet which are firmly within their control.

Objectives: Our aim was to create an engaging and interactive online programme to educate people with RA about heart disease and atherosclerosis. This programme should; explain in simple terms why they are at increased risk; include the opportunity to determine individual risk factors thereby allowing a QRISK2 score to be performed; provide a cognitive-behavioural framework to empower people to change their behaviours and achieve a healthier lifestyle, thereby reducing risk of premature death from heart disease.

Methods: The participant manual created for the group programme and working closely with Dr. John and other health professionals in Dudley (exercise physiologist, smoking cessation nurse, dietician, health psychologist) and patients who had attended the programme, we explored with our creative film production team the best way to adapt this to create a really engaging on-line experience which would allow participants to undertake the programme over time whilst working through the behaviour change goal-setting process. Two days of filming were done in Dudley and Maidenhead followed by a period of editing, additional recording and review. Beta testing of the programme will be conducted in February, piloting in March and launch anticipated for April 2017.

Results: Evaluation of both the programme and the potential to change health behaviours will be measured on completion of the programme and actual behaviour change will be measured at 6 months.

Quote from a patient who participated in the face to face programme: "Before I did this programme I thought that I was doing pretty well in terms of diet and exercise but it showed me that there was a lot I wasn't aware of, that my knowledge of lifestyle factors wasn't adequate and I needed to do more to help myself. I found it a valuable and life-changing experience to do this programme."

Conclusions: We are very excited about the launch of this programme as it is an important new resource addressing the major co-morbidity which shortens the lives of those with RA. It is unique in that not only does it provide patient education, but it also provides a structure through which patient can change their behaviour. Furthermore, it also illustrates what can be achieved when patient-led charity organisations work alongside healthcare professionals; we are hugely excited by its potential.

Disclosure of Interest: None declared

DOI: 10.1136/annrheumdis-2017-eular.6299

\section{AB1251-PARE THE NEEDS AND PRIORITIES OF YOUNG PEOPLE LIVING WITH RHEUMATIC AND MUSCULOSKELETAL DISEASES IN ITALY: A SUB-ANALYSIS OF THE PARE YOUTH RESEARCH PROJECT}

U.G. Viora ${ }^{1}$, S. Ostuzzi ${ }^{2}$, A. Alunno ${ }^{3,4}$ on behalf of ANMAR Italia - ANMAR Young - EULAR Young PARE. ${ }^{1}$ Anmar Italia, Torino; ${ }^{2}$ ANMAR Young, Anmar Italia, Rome; ${ }^{3}$ Rheumatology unit -depy. of Medicine, University of Perugia, Perugia, Italy; ${ }^{4}$ Eular Young Pare, Zurich, Switzerland

Background: In 2014 EULAR Young PARE conducted a research (PARE Youth Research) to gather information about how young people (aged 18-35) living with rheumatic and musculoskeletal diseases (RMDs) are organized in different European countries and to explore their specific needs, obstacles, preferences and priorities. The research was developed through a survey launched in countries with EULAR members organizations and a total of 2,329 validated responses from the target population were obtained. In 2015 ANMAR Young, Italian National Association for people with RMDs' (ANMAR) youth group, was born aimed to create a network of young people with RMDs living in this country.

Objectives: Taken the socio-economical and cultural differences across countries, as well as the need to tailor interventions, activities and projects of national youth groups accordingly, the purpose of this study was to map out specific insights about Italian young people living with RMDs.

Methods: Data from Italian responders to the survey of the PARE Youth Research Project survey were extrapolated and answers were encoded to be analyzed using SPSS 21.0 software. Descriptive statistics were calculated in the whole group as well in subgroups of subjects as needed.

Results: 81 young Italian people living with RMDs responded to the survey: 75 females and 6 males. The conditions reported most often are rheumatoid arthritis $(36 \%)$, juvenile idiopathic arthritis $(23 \%)$, ankylosing spondylitis (15\%). The work on PARE Youth Research's Italian data shows some important insights, among which we highlight that $84 \%$ report a delay in their studies due to the rheumatic condition, $92 \%$ report that the condition has affected their ability to work; $90 \%$ report the impact of RMD on social life, $70 \%$ report an impact on sexual life and $83 \%$ on mental health. Focusing on mental health issues, we highlight that $69 \%$ express the need for psychological support while only $43 \%$ have the possibility to access psychological support. Although all patients reported that after being diagnosed with an RMD they have access to a rheumatologist for regular follow-up visits, an average 3-year diagnostic delay is reported.

Conclusions: The results from the analysis of Italian responders to the survey represent a crucial starting point to put in light the unmet needs of Italian young people living with RMDs. These findings will be of great help to develop a fruitful national network of young people with RMDs on one hand and a focused collaboration with patient representatives, physicians, and health professionals (HPs) on the other. We believe that the awareness of physicians and HPs working in the field of rheumatology about the needs and priorities of young people with RMDs will ensure a better management of the disease and therefore lead to the reduction of the RMD burden in this subgroup of patients.

References:

[1] EULAR Young PARE - Final Report PARE Youth Research Project (2014).

[2] http://www.youngpare.org/wp-content/uploads/2015/05/Finalreport_PARE_Youth.pdf.

Disclosure of Interest: None declared

DOI: 10.1136/annrheumdis-2017-eular.6190

\section{Best practice campaigning}

\section{AB1252-PARE TO RAISE AWARENESS OF RHEUMATIC AND MUSCULOSKELETAL DISEASES AND TO PROVIDE THE OPPORTUNITY TO THE FINANCIALLY LESS ABLE TO RECEIVE TIMELY DIAGNOSIS AND INTERVENTION IN RMDS}

A. Stara, R. Stara, K. Koutsogianni, J. Papadakis, M. Chatziioannou, L. Papadaki, M. Sfakianaki, M. Agapitou. Arthritis Crete, Heraklion, Crete, Greece

Background: The timely and accurate diagnosis in most rheumatic diseases is still a big issue for patients as the choice of the appropriate doctor's specialty is still at the discretion of the patient, mainly due to the poor organized health care services. Furthermore, the success of our campaign two years ago, when we gave the opportunity to people suspecting they might have an RMD but who could not afford a rheumatologist to be examined for free, prompted our organization to offer not only free consultations but free lab tests as well.

Objectives: To raise awareness of RMDs and at the same time to enable people of lower income who may have the early warning signs of rheumatic diseases to be examined by a rheumatologist and have lab tests done at no cost.

Methods: Firstly, we found a sponsor who embraced our initiative and was willing to cover the cost of the whole campaign. Secondly, we contacted various medical laboratories to give us low estimates on the RMD tests and then we chose to collaborate with the ones offering us the lowest prices. Then we came into contact with all the rheumatologists in all the prefectures of the island and asked them to offer consultations free of charge according to their availability. On WAD, 12 October, we erected four stands in four central locations of our island with our logo, a banner, informative leaflets and a large number of well-informed volunteers to answer queries. Prior to WAD we had promoted this special event in the mass and social media. A lot of people visited our stands, told us their problem and their signs and we wrote down the names and phone numbers of those we deemed needed a rheumatologist. As last time, there were people who had already been seeing a rheumatologist who wanted to take advantage 
of this opportunity; we had to reject them as this was only available to people who had not been diagnosed previously. The following two days our office made an appointment for these people with a rheumatologist in their area. The doctors prescribed the necessary laboratory tests and gave a free voucher for the tests to those that needed them. The cost of the lab tests was covered by our association. Our office received a large number of calls from people who wanted to be tested and unfortunately, we could not accommodate all of them as our budget was limited.

Results: More than 267 people visited our stands and 209 people phoned our office asking to be tested. We made appointments for 123 people of whom 111 showed up for their appointments. The rheumatologists gave vouchers and prescribed lab tests for 89 of them. 12 rheumatologists volunteered their services gratis and more than 40 volunteers took part in the campaign.

Conclusions: People's awareness of RMDs is growing but there are still undiagnosed people due to financial constraints, inadequate health insurance coverage and lack of information. Since the demand for free testing is very high we will make every effort to be able to provide this opportunity to undiagnozed people again in the future!

Acknowledgements: BMS

Disclosure of Interest: A. Stara Grant/research support from: BMS

DOI: 10.1136/annrheumdis-2017-eular.2625

\section{AB1253-PARE KID'S GET ARTHRITIS TOO - EXPANSION OF TARGET GROUPS}

\section{Ekroth. The Finnish Rheumatism Association, Helsinki, Finland}

Background: The Finnish Rheumatism Association is generally perceived as a very strong alliance of older people. However in Finland there are more than 2000 children and youth suffering JIA and around 250 new ones get diagnosis yearly. Children will have their whole lives ahead with rheumatic disease, so they and their families also need information, support and friends.

Objectives: Support children and families living with JIA in different ways To provide the accurate and latest information on JIA

Get in touch with families, understand what their needs are, provide them with the correct information and promote their interests

Bring new energy into the families' challenging lives affected by illness

Build a supporting network for the families and increase mental well-being

Rejuvenate the brand of our association

Methods: Ordered international top photographer to photograph the JIA children and families. Created an entirely new high-quality imagery and expression to all Rheumatism Association children communications.

Created the "Puppana" bunny soft toy and the mascot costume.

Have the rheumatism-week campaign: Kids Get Arthritis Too: one week nation wide big radio campaign with a child's voice, a poster campaign in hospitals, our local associations and public spaces.

First aid packet with information of JIA, some toys, and the Puppana mascot. Packets were delivered to all Finnish hospitals, juvenile rheumatoid arthritis units. The rheumatologist gives a packet for a child who receives a diagnosis.
Introduced the action program of two annual nationwide large children's events Joy of Life.

New juvenile rheumatoid arthritis sites for children and families on our new website.

Support the activities of local associations directed for children and families.

Create a new web portal support activities "Reumanakanssa.fi".

International Trials Organisation) in co-operation. Translated into Finnish and added to the new websitewhere we built ABC for JIA.

Results: The brand of the Finnish Rheumatism Association has become more modern and wider.

People have experienced an eye opening campaign, the children suffer from rheumatism-arthritis can be a disease at all ages

Families with children have been reached more, they have joined our social media groups, the event attracted more than 250 children and their families, new families with children have joined the association, some of the local association has begun to organize groups of juvenile rheumatoid arthritis

Fund-raising, it was very easy to find sponsors for children activities and it also helped in common fundraising.

Children suffering from rheumatoid have experienced a positive campaign, it feels better when people's attitudes change, and no longer think that they're suffering from "a disease of the elderly".

Cooperation with arthritis professionals has intensified and improved. Their want to do more co-operation and they guide patients to more actively explore the Finnish Rheumatism Association activities.

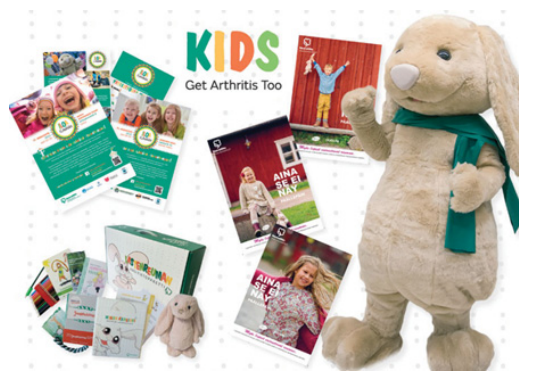

Conclusions: Operation for JIA children and their families are needed.

Children's powerful vision of the activities have a positive impact on the brand and fundraising organization

The positivity of this type of cooperation with arthritis professionals to approximate intervals and supported by more co-operation

It's relatively easy to receive sponsor funds for the development of children's activities

Children and families inclusion will bring new energy and confidence in the future among local associations

Disclosure of Interest: None declared

DOI: 10.1136/annrheumdis-2017-eular.2724 